\title{
Sex differences in rheumatoid arthritis: more than meets the eye... Ronald F van Vollenhoven
}

\author{
Address: Department of Rheumatology, Karolinska University Hospital, 17176 Stockholm, Sweden \\ Email: Ronald F van Vollenhoven - ronald.van.vollenhoven@ki.se
}

Published: 30 March 2009

BMC Medicine 2009, 7:12 doi:10.1 186/1741-7015-7-12

This article is available from: http://www.biomedcentral.com/I74I-70I5/7//2

(c) 2009 van Vollenhoven; licensee BioMed Central Ltd.

This is an Open Access article distributed under the terms of the Creative Commons Attribution License (http://creativecommons.org/licenses/by/2.0), which permits unrestricted use, distribution, and reproduction in any medium, provided the original work is properly cited.
Received: 10 March 2009

Accepted: 30 March 2009

\begin{abstract}
Sex differences in the prevalence of autoimmune diseases such as rheumatoid arthritis (RA) are well described, but the literature is not as clear about sex differences in RA disease course and prognosis. A recent study from a very large cross-sectional international cohort demonstrated slightly worse levels of disease activity and function in female patients with RA, compared with men. These findings are discussed in the context of our evolving knowledge of sex differences in the expression of this prototypic autoimmune disease, both in terms of the actual disease activity level, the effects that the disease has on physical function, and our ability accurately to measure these aspects.
\end{abstract}

\section{Commentary}

Many autoimmune diseases display a striking imbalance between the sexes, with females representing the majority of cases. Thus, autoimmune thyroid diseases, multiple sclerosis, and many of the rheumatological systemic autoimmune diseases such as systemic lupus erythematosus and Sjögren's syndrome affect women more often than men (Table 1, [1-6]). This is also true for rheumatoid arthritis (RA), where the sex ratio is typically around 3:1 [7]. The reasons for this overrepresentation of women are not clear, but genetic (X-linked) factors and hormonal aspects are likely to be involved [8-13].

RA is a relatively common chronic autoimmune inflammatory disease that affects the synovial joints, and with time causes significant functional losses due to persistent inflammatory activity in the joints, destruction of bone and cartilage, and extra-articular disease manifestations. In addition to an imbalance in the prevalence as noted above, RA may also have an imbalance in disease course and prognosis. Many observational studies have suggested that, on the whole, women with RA do worse than men with the disease [14-18]. However, this issue is not as straightforward as it may seem. First of all, the observational data cited are not all in agreement, and some studies have not supported them. Second, because of the very long follow-up times required, such data are always subject to various biases. Third, it is not entirely clear what kind of 'doing worse' is most relevant. For instance, the fact that functional outcomes are worse in female patients may be attributed to the fact that greater muscle strength in men allows them to compensate in a more successful manner for functional losses, and not for differences in the disease per se. Finally, if the disease course in women is, indeed, more grave than in men, then the question is raised whether this is due to a) an inherent difference in the biology of the disease; b) a difference in the manner in which men and women respond to therapy; or c) the therapies given to men and women with the disease (Figure $1)$.

Recently, Sokka et al [19] published an analysis based on an exceptionally large international cohort of RA patients, the QUEST-RA study. This cohort of more than 6000 patients, recorded at 70 sites in 25 participating countries, was cross-sectionally analyzed with respect to demo- 
Table I: Sex ratio in various rheumatological diseases.

\begin{tabular}{ll}
\hline Disease & Female:male ratio \\
\hline Sjögren's syndrome & $9: 1[1]$ \\
\hline Systemic lupus erythematosus & $7: 1[2]$ \\
\hline Rheumatoid arthritis & $3: 1[3]$ \\
\hline Systemic sclerosis & $3: 1[4]$ \\
\hline Psoriatic arthritis & $1: 1[5]$ \\
\hline Ankylosing spondylitis & $1: 3[6]$ \\
\hline
\end{tabular}

graphics and disease activity parameters. The authors analyzed the 'core set' disease activity parameters for RA, an internationally agreed-upon set of seven measurements considered highly relevant for the assessment of RA [20]. These include the swollen joint count (SJC): the number of joints that are objectively swollen as determined by the examining physician, out of a prespecified number of joints, usually 68 in the case of clinical trials, but reduced to a more manageable 28 in the case of observational studies, as was done here. The SJC is generally perceived as a very 'objective' measure of RA disease activity. Other core set measures include:

a) the tender joint count (TJC) where joints are counted that are tender to palpation;

b) the patient's assessment of global disease activity on a visual analogue scale (VAS);

c) the patient's assessment of pain by VAS - these latter three outcomes are more obviously 'subjective' in nature;

d) the physician's assessment of disease activity, also usually done by VAS, and sometimes considered the gold standard;

e) an acute-phase reactant, either the C-reactive protein or the erythrocyte sedimentation rate;

f) the health-assessment questionnaire disability index (HAQ), which is not truly a measure of disease activity but of function - which can be influenced by disease activity but also by permanent damage.

A combination of four out of these seven core-set measures allows calculation of the disease activity score (DAS, or DAS28 if SJC and TJC are based on 28 joints) which gives a summary in one single number $[21,22]$. Finally,
DAS-based cut-offs can be used to define patients considered to be in remission $[23,24]$.

In the QUEST-RA study by Sokka et al [19], it was found that all core-set measures were higher in the female patients (representing $79 \%$ of the patients) than in the male ones, in apparent support of the thesis that female patients with RA 'do worse'. However, when calculating the differences as effect sizes, that is, asking the question how much of a difference in outcome could be attributed to the sex difference, rather small estimates were obtained, and smallest for the SJC. In addition, it was determined that women with only one swollen joint or none had significantly higher levels of subjective disease activity, and also a higher DAS28, than men. This resulted in a lower percentage of females who would be considered by DAS28 to be in remission. The authors conclude that "RA disease activity measures appear worse in women than in men, [but that] most of the gender differences ... may originate from the measures of disease activity rather than from RA disease activity itself."

This study is respectable in terms of its purpose and scope, and enviable for its patient material. Nonetheless, it is not completely clear what these data mean. Several important aspects are touched upon, but not all can be addressed entirely satisfactorily. The first key issue is whether there is a sex difference in the course of RA: do women in fact 'do worse'? On several points this study simply cannot provide the answer. The most dramatic and definitive long-term outcome in RA is mortality: many studies have shown that patients with RA die mostly of the same causes as others, but they die younger, presumably due to the long-term consequences of the disease in terms of natural immunity, cancer surveillance, atherogenesis, etc [25-27]. No crosssectional study could ever demonstrate whether there is a difference in this outcome. To the contrary, 'left-censoring', the fact that patients who did have the worst disease might have died before being able to contribute to the cohort, could have attenuated any true difference between the sexes. The second key issue has to do with physical function in patients with RA. A sex difference in functional capacity for patients with RA has been noted previously and was also confirmed in this study, with women having more functional impairment than men, but this finding is open to different interpretations. It could be a difference in disease course, but also a difference between the ability of men and women to compensate for any functional losses in daily life (primarily due to the above-mentioned difference in muscle strength, but also in bone mineral density, skin thickness and so on). Indeed, the most widely used measure of function, the HAQ, is cross-sectionally always higher (worse) in women.

In order to settle these and related questions more definitively longitudinal studies of large cohorts of patients are 


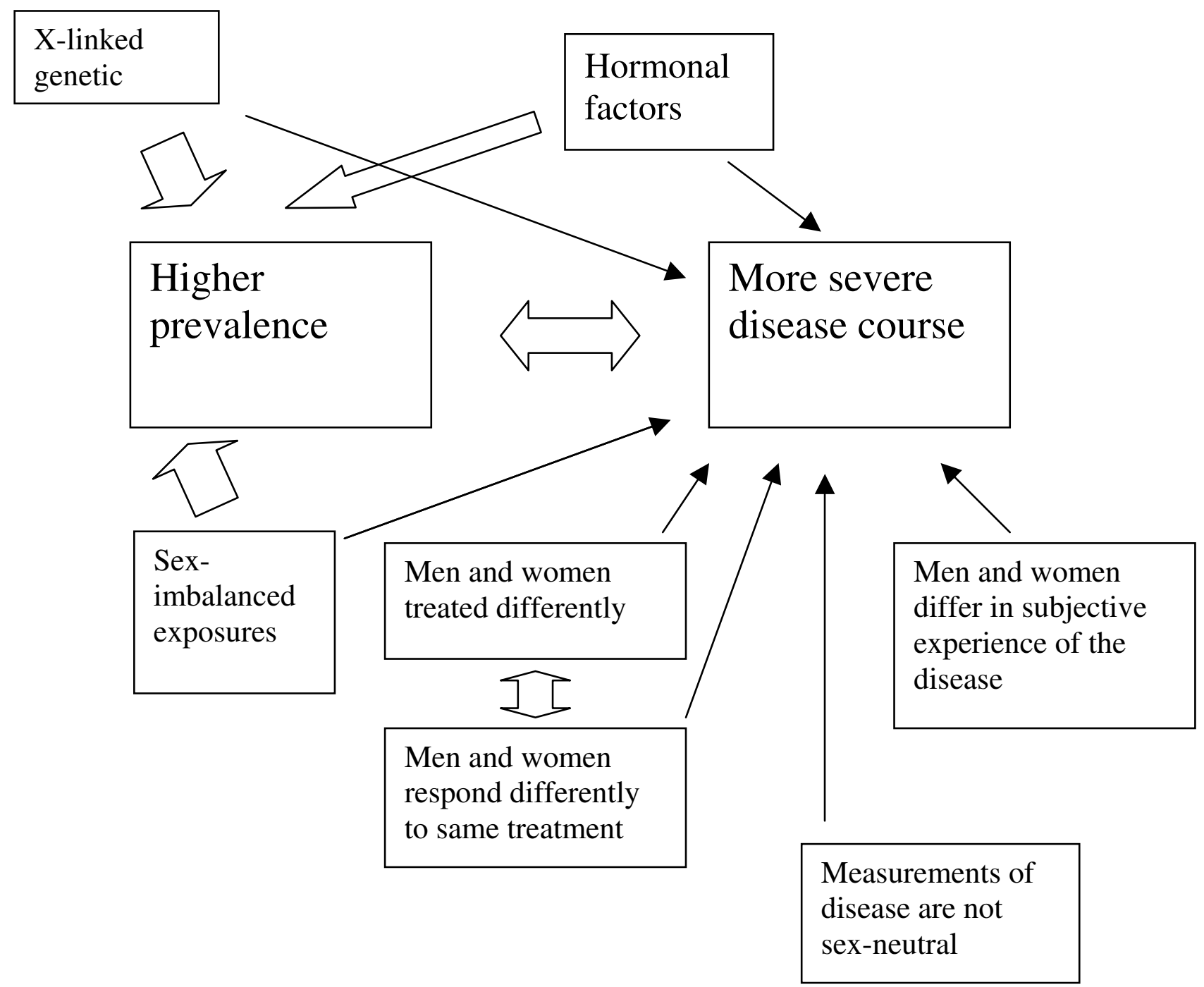

Figure I

$X$-linked genetic factors, hormonal factors, and exposures that may be different for men and women could all influence the prevalence of autoimmune diseases as well as their severity. The latter aspect is, however, also influenced by many more factors, including differences in the treatments given, the response to treatments, the subjective experience of the disease, and the instruments used to measure the disease. The thick arrows indicate established associations and the thin arrows putative associations.

going to be needed. The QUEST-RA group may be well positioned to perform such studies and we are eagerly awaiting such data. Randomized trials, which by necessity are more restrictive and of shorter duration, may also provide valuable insight into any true sex differences in the course and prognosis of RA. Ultimately, such results may impact on our understanding of autoimmune diseases as well as on their treatment, for instance, by having sex-specific treatment algorithms if outcomes can be shown to differ by sex and by medication.

Finally, the conclusion drawn by Sokka et al, that differences between the sexes are explained by the measurement of the disease rather than by the disease itself, is an interesting one, but perhaps not fully supported by their data. This touches on a somewhat sensitive issue that we recently investigated at our unit [28]. The point is this: if the 'objective' disease, that is, the amount of inflammation in the joints, is identical, but the female patient experiences this as 'more' disease, that is, more pain, more stiffness, more generalized distress, and more functional deterioration, is it then fair to say that the disease nonetheless is identical? This would reflect, in my opinion, a rather limited biological perspective. Before dwelling on that, let me clarify that we do not yet know that this is indeed the case. However, if it were true it should not come as a surprise: it is well 
established, for instance, that given the same noxious stimulus female experimental subjects experience a slightly higher degree of physical pain; that is, the pain threshold is lower [29-33] (this has nothing to do with the fact that women may be, according to widely held belief, 'tougher' when it comes to coping with pain). If that is indeed the case, should not then our assessment of how serious the disease really is also take into account the subjective dimension, the suffering imparted by the disease on the patient? It would appear to me that this is particularly true for those of us who practise (or teach the art of) medicine. After all, when we treat our patients, we do so in order to alleviate their suffering. And although the variability of subjective experiences and expressions compels us to be very dependent on objective data, we certainly must never forget to whom we owe our first obligation.

\section{Competing interests}

The author declares that he has no competing interests.

\section{References}

I. Talal N: Sjögren's syndrome: historical overview and clinical spectrum of disease. Rheum Dis Clin North Am 1992, I 8:507-5I 5.

2. Fessel W]: Systemic lupus erythematosus in the community. Incidence, prevalence, outcome and first symptoms; the high prevalence in black women. Arch Intern Med 1974, 134: 1027-1035.

3. Linos A, Worthington JW, O'Fallon WM, Kurland LT: The epidemiology of rheumatoid arthritis in Rochester, Minnesota: a study of incidence, prevalence and mortality. Am J Epidemiol | 980, I | | :87-98.

4. Steen V, Conte C, Santoro D, et al.: Twenty-year incidence survey of systemic sclerosis (scleroderma). Arthritis Rheum 1980, 23:58I-590.

5. Moll JM, Wright V: Psoriatic arthritis. Semin Arthritis Rheum I973, 2:|8|-20|.

6. Will R, Edmunds L, Elswood J, Calin A: Is there sexual inequality in ankylosing spondylitis? A study of 498 women and 1202 men. J Rheumatol 1990, I 7:1649-1652.

7. Wolfe AM, Kellgren JH, Masi AT: The epidemiology of rheumatoid arthritis: a review. II. Incidence and diagnostic criteria. Bull Rheum Dis 1968, 19:524-529.

8. Van Vollenhoven RF, McGuire JL: Estrogen, Progesterone, and Testosterone: Can they be used to treat Autoimmune Diseases? Cleveland Clinic J Med 1994, 6 1:276.

9. Cutolo M, Villaggio B, Seriolo B, Montagna P, Capellino S, Straub RH, Sulli A: Synovial fluid estrogens in rheumatoid arthritis. Autoimmun Rev 2004, 3:193-198.

10. Wilder RL: Hormones, pregnancy, and autoimmune diseases. Ann N Y Acad Sci 1998, 840:45-50.

II. Cutolo M, Sulli A, Capellino S, Villaggio B, Montagna P, Seriolo B, Straub RH: Sex hormones influence on the immune system: basic and clinical aspects in autoimmunity. Lupus 2004, I 3:635-638.

12. Olsen NJ, Kovacs WJ: Hormones, pregnancy, and rheumatoid arthritis. I Gend Specif Med 2002, 5:28-37.

13. O'Brien SM, Fitzgerald P, Scully P, Landers A, Scott LV, Dinan TG: Impact of gender and menstrual cycle phase on plasma cytokine concentrations. Neuroimmunomodulation 2007, 14:84-90.

14. Forslind K, Hafstrom I, Ahlmen M, Svensson B: Sex: a major predictor of remission in early rheumatoid arthritis? Ann Rheum Dis 2007, 66:46-52.

15. Tengstrand B, Ahlmen M, Hafstrom I: The influence of sex on rheumatoid arthritis: a prospective study of onset and outcome after 2 years. J Rheumatol 2004, 3 I:2 I 4-222.
16. Symmons DP: Epidemiology of rheumatoid arthritis: determinants of onset, persistence and outcome. Best Pract Res Clin Rheumatol 2002, I 6:707-722.

17. Kuiper S, van Gestel AM, Swinkels HL, de Boo TM, da Silva JA, van Riel PL: Influence of sex, age, and menopausal state on the course of early rheumatoid arthritis. J Rheumatol 200I, 28: $1809-1816$.

18. Da Silva JA, Hall GM: The effects of gender and sex hormones on outcome in rheumatoid arthritis. Baillieres Clin Rheumatol 1992, 6:196-219.

19. Sokka T, Toloza S, Cutolo M, Kautiainen H, Makinen H, Gogus F, Skakic V, Badsha H, Peets T, Baranauskaite A, Géher P, Ujfalussy I, Skopouli FN, Mavrommati M, Alten R, Pohl C, Sibilia J, Stancati A, Salaffi F, Romanowski W, Zarowny-Wierzbinska D, Henrohn D, Bresnihan B, Minnock P, Knudsen LS, Jacobs JW, Calvo-Alen J, Lazovskis J, Pinheiro GD, Karateev D, Andersone D, Rexhepi S, Yazici Y, Pincus T, the QUEST-RA Group: Women, men, and rheumatoid arthritis: analyses of disease activity, disease characteristics, and treatments in the QUEST-RA study. Arthritis Res Ther 2009, I I:R7.

20. Felson DT, Anderson JJ, Boers M, Bombardier C, Furst D, Goldsmith C, Katz LM, Lightfoot R Jr, Paulus H, Strand V, et al.: American College of Rheumatology. Preliminary definition of improvement in rheumatoid arthritis. Arthritis Rheum 1995, 38:727-735.

21. Heijde DMFM Van der, van't Hof MA, van Riel PLCM, Putte LBA van de: Development of a disease activity score based on judgement in clinical practice by rheumatologists. J Rheumatol 1993, 20:579-58I.

22. Prevoo ML, van't Hof MA, Kuper HH, van Leeuwen MA, Putte LB van de, van Riel PL: Modified disease activity scores that include twenty-eight-joint counts. Development and validation in a prospective longitudinal study of patients with rheumatoid arthritis. Arthritis Rheum 1995, 38:44-48.

23. van Gestel AM, Prevoo ML, van't Hof MA, van Rijswijk MH, Putte LB van de, van Riel PL: Development and validation of the European League Against Rheumatism response criteria for rheumatoid arthritis. Arthritis Rheum 1996, 39:34-40.

24. Fransen J, Creemers MC, Van Riel PL: Remission in rheumatoid arthritis: agreement of the disease activity score (DAS28) with the ARA preliminary remission criteria. Rheumatology (Oxford) 2004, 43: I 252-I 255.

25. Reah TG: The prognosis of rheumatoid arthritis. ( 85 patients followed up over I3 years). Proc $R$ Soc Med 1963, 56:813-8I7.

26. Aviña-Zubieta JA, Choi HK, Sadatsafavi M, Etminan M, Esdaile JM, Lacaille D: Risk of cardiovascular mortality in patients with rheumatoid arthritis: a meta-analysis of observational studies. Arthritis Rheum 2008, 59:1690-1697.

27. Gabriel SE: Why do people with rheumatoid arthritis still die prematurely? Ann Rheum Dis 2008, 67(Suppl 3):iii30-34.

28. Riley JL 3rd, Robinson ME, Wise EA, Myers CD, Fillingim RB: Sex differences in the perception of noxious experimental stimuli: a meta-analysis. Pain 1998, 74:I8I-I87.

29. Joelsson J, Van Vollenhoven RF: RA: different for her than for him? - Gender differences in RA therapeutics. Oral presentation, International Congress on Gender Medicine 2008.

30. Riley JL 3rd, Robinson ME, Wise EA, Price DD: A meta-analytic review of pain perception across the menstrual cycle. Pain 1999, 8 |:225-235.

31. Unruh AM: Gender variations in clinical pain experience. Pain 1996, 65:123-167.

32. Bingefors K, Isacson D: Epidemiology, co-morbidity, and impact on health-related quality of life of self-reported headache and musculoskeletal pain - a gender perspective. Eur J Pain 2004, 8:435-450.

33. Smith YR, Stohler CS, Nichols TE, Bueller JA, Koeppe RA, Zubieta JK: Pronociceptive and antinociceptive effects of estradiol through endogenous opioid neurotransmission in women. J Neurosci 2006, 26:5777-5785.

\section{Pre-publication history}

The pre-publication history for this paper can be accessed here:

http://www.biomedcentral.com/1741-7015/7/12/prepub 